Simões, R. H. S.

"Da avaliação da educação à educação da avaliação: o lugar do(a) educador(a) no processo da avaliação da pós-graduação no Brasil"

\title{
DA AVALIAÇÃO DA EDUCAÇÃO À EDUCAÇÃO DA AVALIAÇÃO: O LUGAR DO(A) EDUCADOR(A) NO PROCESSO DA AVALIAÇÃO DA PÓS-GRADUAÇÃO NO BRASIL
}

Regina Helena Silva Simões

Universidade Federal do Espírito Santo

RESUMO: Ete artigo aborda o debate sobre o modelo de avaliação adotado pela CAPES para os programas de pós-graduação nas universidades brasileiras, propondo a seguinte reflexão: que ensino e que pesquisa acontecem (e especialmente deixam de acontecer) enquanto tentamos nos "ajustar" ao modelo de avaliação vigente, caracterizado pelo viés empresarial? Essa linha de pensamento compreende três momentos: o primeiro é dirigido à análise da universidade em tempos neoliberais; o segundo, trata de pressupostos subjacentes ao modelo de avaliação da pós-graduação e o terceiro busca mapear o lugar do educador nesse processo, apontando como campo de possibilidade a avaliação pensada e conduzida principalmente pela ótica de educadores e educadoras e não pela ótica da tecnocracia (papel que freqüentemente temos sido chamados a assumir).

PALAVRAS-CHAVE: avaliação, universidade, CAPES, CNPq.

\section{FROM EVALUATION OF EDUCATION TO EDUCATION OF EVALUATION: THE EDUCATOR'S ROLE IN THE UNIVERSITARY EVALUATION PROCESS}

ABSTRACT: This article approaches the debate about the evaluation model adopted by CAPES for Post-Graduation programs in Brazilian universities, proposing the following reflection: what teaching and research are happening (and specially are not happening) while we try to "adjust" ourselves to the current evaluation model, characterized by enterprising bias? This line of thinking contains three moments: the first one goes towards an analysis of universities in neoliberal times, the second one deals with subjacent 
Psicologia \& Sociedade; 16 (1): 124-134; Número Especial 2004

presuppositions to Post-Graduation evaluation model and the third one seeks to trace the educator's role in this process, pointing as a field of possibility an evaluation thought and led mainly through the view of educators and not through the view of technocracy (a role that we have often been called to assume).

KEYWORDS: evaluation, university, CAPES, CNPq.

O debate sobre o modelo de avaliação adotado pela CAPES mostra-se especialmente necessário no momento em que, como se sabe, o Conselho Nacional de Desenvolvimento Científico e Tecnológico $(\mathrm{CNPq})$ propõe a reformulação dos cursos de pós-graduação no Brasil.

Comentando a iniciativa do CNPq, Luís Nassif $(2003)^{1}$ analisa a pós-graduação e a economia no Brasil. Segundo o autor, ao instituir a quantidade de trabalhos publicados em periódicos especializados estrangeiros como o critério de excelência na avaliação dos programas de pós-graduação no Brasil, a comunidade científica deu um passo correto para eliminar o "compadrio corporativo". Por outro lado, distorções teriam sido criadas a partir dessa escolha, sendo a principal delas a utilização das publicações internacionais como "único critério de avaliação" da produção acadêmica no Brasil.

$\mathrm{Na}$ área econômica, segundo o autor, o quadro acima descrito tem gerado um "falso universalismo da teoria econômica" com reflexos previsíveis nas decisōes econômicas, freqüentemente tomadas "[...] como se a última teoria em voga tivesse abolido as diferenças entre as diversas realidades econômicas e conquistado a universalidade" (p. B3).

Sendo a educação um campo atravessado por múltiplos saberes, múltiplas implicações e incontáveis (às vezes inconfessáveis) interesses, evidentemente o falso universalismo de teorias cunhadas não só na economia mas nas mais diversas áreas do conhecimento repercute diretamente na definição das políticas educacionais no Brasil, por meio das quais, via de regra, busca-se atender a normas

1 Em artigo publicado na FOLHA DE SÃO PAULO, 23-5-2003, p.B3. 
Simões, R. H. S.

"Da avaliação da educação à educação da avaliação: o lugar do(a) educador(a)

no processo da avaliação da pós-graduação no Brasil"

ditadas por organismos internacionais, em detrimento das necessidades e dos desejos expressos por segmentos acadêmicos e sociais brasileiros.

O modelo de avaliação aplicado pela CAPES à pós-graduação no Brasil, objeto da nossa análise, não parece capaz de contemplar a diversidade e a heterogeneidade necessárias à prática da educação na academia e fora dela. Portanto, ao analisar a avaliação do pós-graduação nas universidades brasileiras, proponho, inicialmente, como ponto de reflexão, o seguinte: que ensino e que pesquisa acontecem (e especialmente deixam de acontecer) enquanto tentamos nos "ajustar" ao modelo de avaliação vigente?

Alinhando-me entre aqueles e aquelas que valorizam positivamente todo o percurso da avaliação da pós-graduação brasileira e que, por conseguinte, postulam um constante aperfeiçoamento do processo, aponto como campo de possibilidade a avaliação pensada e conduzida principalmente pela ótica de educadores e educadoras e não pela ótica da tecnocracia (papel que freqüentemente temos sido chamados a assumir).

Ao fazê-lo, utilizo como fontes as obras de Chauí (2001), Santos (1997) e Mendes (1987), cujas idéias julgo fundamentais à compreensão dos desafios postos à universidade contemporânea, dos pressupostos subjacentes ao modelo de avaliação proposto para a pós-graduação no Brasil e do lugar do educador no processo de avaliação da pós-graduação.

\section{OS DESAFIOS POSTOS À UNIVERSIDADE CONTEMPORÂNEA}

A crise do Estado Providência, associada à ampliação das demandas sociais dirigidas ao serviço público no Brasil, tem gerado desafios de difícil enfrentamento às universidades públicas. Como observa Santos (1997), ${ }^{2}$ a dificuldade na resposta a essas demandas não tem caráter apenas conjuntural, uma vez que

2 Embora tome como referência a realidade européia, a reflexão proposta por Santos parece-me pertinente à análise da universidade brasileira, uma vez que o autor discute, dentre outros aspectos, a "idéia universal" de universidade e a sua carga simbólica. O autor cita, inclusive, obras de Marilena Chauí e José Arthur Giannotti. 
$=$ Psicologia \& Sociedade; 16 (1): 124-134; Número Especial 2004

[...] a perenidade da instituição universitária, sobretudo no mundo ocidental, está associada à rigidez funcional e organizacional, à relativa impermeabilidade às pressōes externas, enfim, à aversão à mudança (p. 187).

$\mathrm{Na}$ década de sessenta, a aparente continuidade dos objetivos originalmente expressos pelas universidades foi abalada. Os fins propostos para a instituição universitária passaram a compreender: a pesquisa, o ensino e a prestação de serviços. Historicamente,

[...] apesar da inflexão ser, em si mesma, significativa e de se ter dado no sentido do atrofiamento da dimensão cultural da universidade e do privilegiamento do seu conteúdo utilitário, produtivista, foi sobretudo ao nivel das politicas universitárias concretas que a unicidade dos fins abstratos explodiu numa multiplicidade de funçôes por vezes contraditórias entre si (SANTOS, 1997, p. 188).

Ilustrando a multiplicidade de funçôes, vale a pena observar que, em 1987, o relatório da Organização de Cooperação e de Desenvolvimento Econômico (OCDE) atribuía à universidade as seguintes responsabilidades:

[...] educação geral pós-secundária; investigação; fornecimento de mão-de-obra qualificada; educação e treinamento altamente especializados; fortalecimento da competitividade da economia; mecanismo de seleção para empregos de alto nivel de credencialização; mobilidade social para os filhos e filhas de familias operárias; prestação de serviços à regiāo e à comunidade local; paradigmas de aplicação de politicas nacionais (ex. Igualdade de oportunidades para mulheres e minorias raciais); preparação para os papéis de liderança social (apud SANTOS, 1997, p. 189).

Permanece então o desafio: como gerir essa multiplicidade de funções freqüentemente incompatíveis entre si? Estaria a universidade preparada para fazê-lo? Segundo Santos, ao lidar com essa questão, em meio à crise de hegemonia, de legitimidade e à crise institucional, a universidade tem optado pela administração das tensões, sem livrar-se das contradições que as produzem. Uma dessas contradições, com profundo impacto no processo de avaliação institucional, diz respeito à 
Simões, R. H. S.

"Da avaliação da educação à educação da avaliação: o lugar do(a) educador(a) no processo da avaliação da pós-graduação no Brasil"

[...] reivindicação da autonomia na definição dos valores e dos objetivos institucionais e à submissão crescente a critérios de eficácia e de produtividade de origem e natureza empresarial (SANTOS, 199, p. 190).

Esses critérios, marcadamente presentes no modelo de avaliação proposto para a educação brasileira em diferentes níveis de ensino e, especificamente, o seu impacto no cotidiano dos programas de pós-graduação, constituem o foco seguinte da análise aqui proposta.

\section{SOBRE A AVALIAÇÃO DA PÓS-GRADUAÇÃO NO BRASIL: DO DARWINISMO ACADÊMICO À CONSTRUÇÃO DA "EXCELÊNCIA"}

Segundo Chauí (2001), no contexto autoritário da sociedade brasileira, na qual o Estado de Bem-Estar sequer foi realmente instaurado, "[...] o neoliberalismo parece [à primeira vista] uma aberração, o pós-modernismo parece mais uma idéia fora do lugar e a terceira via um catecismo para incréus" (p. 34). No entanto, diz a autora:

[...] observando mais de perto o neoliberalismo nos cai como uma luva porque afirma idéias e práticas antidemocráticas; o pós-modernismo politico nos assenta muito bem porque reforça o personalismo e responde adequadamente à forte tradição populista de nossa politica; e a terceira via oferece um discurso apaziguador que dissolve contradiçôes e conflitos [...] com a transferência das responsabilidades estatais para a benemerência dos ricos com relação aos pobres, reforçando a tradição assistencialista da sociedade brasileira (p. 34).

Ao analisar o impacto neoliberal na vida universitária, Chauí (2001) evidencia o caráter hegemônico assumido pelos seguintes temas no interior da academia:

1) a avaliação da universidade desvinculada dos outros niveis de ensino, como se nenhuma responsabilidade the coubesse na situação em que se encontram; 2) a avaliação acadêmica pelo critério 
$=$ Psicologia \& Sociedade; 16 (1): 124-134; Número Especial 2004

da titulação e das publicaçôes, em detrimento da docência; 3) a distribuição de recursos por linhas de pesquisa, critério apropriado para as áreas em que pesquisadores se agrupam em torno de laboratórios, mas sem sentido quando se trata das ciências humanas $e$ dos campos de pesquisa teórica fundamental; e 4) a idéia de modernização racionalizadora pela privatização e terceirização da atividade universitária, a [...] universidade como prestadora de serviços às empresas privadas, em detrimento da pesquisa fundamental e de longo prazo (p. 35-36).

No vácuo do Estado Providência, os cortes orçamentários, especialmente na área das ciências humanas e sociais, juntam-se à concorrência do setor privado. Esses cortes, como se sabe, por serem seletivos, afetam diretamente as relações internas de poder na medida em que alteram as posições relativas das áreas do saber, uma vez que os recursos passam a priorizar a "excelência" estabelecida com base em critérios marcados pelo colonialismo, pela ênfase ao modelo científico das chamadas "ciências duras" e pelo viés empresarial.

Como observa Santos (1997), na medida em que os cortes orçamentários são propostos com base no discurso da produtividade, a universidade passa a

[...] questionar-se em termos que the são pouco familiares e a submeter-se a critérios de avaliação que tendem a dar do seu produto, qualquer que ele seja, uma avaliação negativa (p. 214).

Em última análise, segundo o autor,

[...] a participação da universidade na luta pela produtividade acabou por virar essa luta contra a própria universidade e o impacto institucional dai decorrente não se fez esperar (p. 215).

Configura-se, dessa forma, uma lógica empresarial imediatista, em contraposição ao médio e longo prazo característicos da lógica institucional universitária. $\mathrm{O}$ viés empresarial imposto à avaliação, por sua vez, exerce um impacto imediato em relação às "escolhas" e às prioridades docentes e discentes. Não é por acaso que nos referimos à produção acadêmico-científica dos programas de pós-graduação (significando especialmente a quantidade de trabalhos publicados) 
Simões, R. H. S.

"Da avaliação da educação à educação da avaliação: o lugar do(a) educador(a)

no processo da avaliação da pós-graduação no Brasil"

e medimos a produtividade docente em número de aulas dadas. A ênfase ao curto prazo, evidenciada na avaliação da produção acadêmica, torna-se especialmente perigosa na medida em que "[...] a universidade é uma das poucas instituições da sociedade contemporânea onde é ainda possível pensar em longo prazo e agir em função dele" (SANTOS, 1997, p. 218).

Não deve ser motivo de admiração, portanto, a postura defensiva das universidades no que se refere à avaliação de desempenho externo, em contraposição ao apego a práticas de avaliação internamente instituídas. Ocorre que os critérios da avaliação externa tendem a ignorar a especificidade das instituições universitárias, gerando um inevitável estranhamento entre o modo como a universidade pensa a si mesma e o modelo de avaliação proposto pelo Ministério da Educação.

Santos (1997) assinala três pontos relacionados com a avaliação da universidade: a definição do "produto" universitário, os critérios e a titularidade da avaliação. Tendo em vista os múltiplos fins atribuídos à universidade, o autor questiona qual seria, de fato, o "produto" universitário. Mais ainda, questiona a propriedade de falarmos em produto quando se trata da avaliação do desempenho de universidades. Admitindo-se a idéia de produto, uma outra questão emerge: como "capturar" a qualidade e a eficácia, quando os "produtos" da universidade freqüentemente escapam à mensuração direta (p. 216).

Evidentemente, o viés quantitativo apontado não pode e não deve ser aceito como resposta a essa questão. Superá-lo, portanto, parece ser um desafio dirigido aos professores e investigadores universitários, principalmente (mas não exclusivamente) no campo das ciências humanas e sociais em que as distorções provocadas pelo viés quantitativo são especialmente visíveis e nefastas. Esse desafio requer como resposta um ativo engajamento das universidades na definição dos seus próprios objetivos. Estabelece ainda a democratização interna como condição necessária ao desenvolvimento de ações externas, visando a instituir, com sucesso, novas formas de avaliação. Em outras palavras: não há "força exterior" sem "força interna" (SANTOS, 1997, p. 221).

Giannotti (apud SANTOS, 1997, p. 221) enfatiza a importância da avaliação interpares conduzida "[...] por gente da comu- 
Psicologia \& Sociedade; 16 (1): 124-134; Número Especial 2004

nidade acadêmica capaz de distanciar-se do clielentelismo de cada centro". De fato, no modelo brasileiro, a avaliação externa interpares tem sido justamente apontada como uma importante conquista. Entretanto, não podemos esquecer que o seu exercício se dá em um contexto marcado pelo autoritarismo das políticas públicas engendradas sob a orquestração das agências internacionais de financiamento cujo objetivo tem sido a redução do investimento na área social. Desenha-se, dessa forma, uma difícil equação: juntar a máxima qualidade ao mínimo de investimento, em meio ao desequilíbrio das relações de poder estabelecidas entre instituições e áreas de conhecimento.

Se a própria universidade carece de "[...] poder social e político para impor condiçôes que garantam uma avaliação equilibrada e despreconceituosa do seu desempenho [...]" (SANTOS, 1997, p. 220), o que dizer então do lugar reservado, por exemplo, à área social (e especificamente à educação) no movimento altamente competitivo, escassamente financiado e tecnocraticamente gerenciado da avaliação do desempenho da pós-graduação?

Em outras palavras: não basta instituirmos comissões interpares, ainda que "livres de clientelismo", se o processo de avaliação for gerenciado de forma meramente tecnocrática e o diálogo entre as áreas de conhecimento for atravessado pela competição por recursos mínimos, cujos resultados serão necessariamente excludentes. Portanto, ainda que os critérios da avaliação espelhem diretrizes caras à tecnocracia, ao final, trata-se de uma questão política e como tal deve ser tratada. Até porque, em última análise,"[...] as abordagens tecnocráticas da avaliação escondem a fraqueza política da universidade, sobretudo da universidade pública" (SANTOS, 1997, p. 220).

Em face ao exposto, proponho a seguir, como ponto de reflexão, o lugar dos(as) professores(as) pesquisadores(as) que atuam no processo de avaliação da pós-graduação. 
Simões, R. H. S.

"Da avaliação da educação à educação da avaliação: o lugar do(a) educador(a) no processo da avaliação da pós-graduação no Brasil"

\section{DA AVALIAÇÃO DA EDUCAÇÃO À EDUCAÇÃO DA AVALIAÇÃO: O LUGAR DO EDUCADOR NA AVALIAÇÃO DA PÓS-GRADUAÇÃO NAS UNIVERSIDADES BRASILEIRAS}

Ao final do século XX, Santos (1997) descreveu as universidades como instituiçôes reativas, dependentes e imediatistas, cedendo a pressóes e incorporando acriticamente lógicas sociais e institucionais externas. Por isso afirma que "[...] o grande perigo para a universidade é o de os dirigentes universitários se limitarem a liderar inércias" (p. 226).

Mendes (1987) definiu o tecnocrata como "demiurgo fácil" (p. 59) que, ao associar a habilidade técnica ao poder,

[...] mistura dois poderes: o de fazer com facilidade e o de impor com facilidade. Ou seja, poderá ordenar nos dois sentidos: de formular a ordem e de torná-la imperativa, com uma racionalidade desembaraçada de todos os empecilhos do real. Por isso mesmo o tecnocrata desse tipo é, por excelência, o antieducador (p. 59-60).

No entanto, para o autor, instituição universitária poderia se contrapor ao modo tecnocrático porque, sendo

[...] capaz de produzir um estilo diferenciado de reflexão, concorre para formar um estilo universal e aberto de cultura (vocação originária da própria Universidade) (p. 114).

A aposta na capacidade de reflexão crítica da instituição universitária também se encontra presente no pensamento de Santos (1997), para quem "[...] a universidade é talvez a única instituição nas sociedades contemporâneas que pode pensar até as raízes as razões por que não pode agir em conformidade com o seu pensamento" (p. 225). Desafiador, proclama: “[...] na fase de transição paradigmática, a universidade tem que ser a alternativa à universidade" (p. 225).

Analisando o papel da instituição universitária, o autor conclui que

[...] a [sua] mera permanência institucional faz com que a sua existência material tenha uma dimensão simbólica particularmente densa. Essa dimensão é um recurso inestimável, mesmo que os simbolos em que se tem traduzido devam ser substituidos (p. 230) 
$=$ Psicologia \& Sociedade; 16 (1): 124-134; Número Especial 2004

Acreditando que o (re)encantamento da universidade possa constituir "[...] uma das vias para simbolizar o futuro uma vez que a "vida cotidiana universitária tem um forte componente lúdico que favorece a transgressão simbólica do que existe e é racional só porque existe [...]", propõe que a universidade assuma o seu papel "[...] no re-encantamento da vida coletiva sem o qual o futuro não é apetecível, mesmo se viável" (p. 230).

Naturalmente isso não é tarefa para tecnocratas. Ao contrário, como sugere Mendes, trata-se de um trabalho para educadores que se propõem a compreender, "[...] antes de qualquer coisa, os ritmos, longos, densos e, às vezes, imprevisíveis que a práxis engendra e articula para dentro e para fora de cada [ser humano]" (p. 60). Essa é, em meu ponto de vista, uma lógica interessante a partir da qual vale a pena pensar a avaliação da universidade. Até porque, quando reduzimos as questôes da avaliação universitária à esfera da tecnocracia, como sugere Chauí (2001), simplesmente perdemos "[...] o lugar da batalha" (p. 38).

Por isso, como reafirmar, no contexto da avaliação da pósgraduação brasileira, o lugar do educador? Começaria lembrando o óbvio feito pouco visível: que, independentemente da área do conhecimento em que se atue, a avaliação da pós-graduação, em última análise, avalia educação e educadores. Portanto, sendo professora do curso de Pedagogia e da pós-graduação em educação, falo de um lugar especialmente marcado, mas necessariamente compartilhado pelos docentes/pesquisadores/cientistas que atuam em todos os campos do conhecimento: o lugar da formação humana.

Dessa forma, gostaria de convidá-los a refletir sobre a avaliação da pós-graduação não apenas como a quantificação e a internacionalização da produção científica, mas principalmente como elemento norteador de novas formas de pensar e viver a experiência humana, com o objetivo da torná-la mais digna e inclusiva. Para tanto, não basta avaliar a educação; é preciso, antes de tudo, educar a avaliação, privilegiando critérios de qualidade, diversidade e inclusão e não apenas de quantificação, competitividade e exclusão. 
Simões, R. H. S.

"Da avaliação da educação à educação da avaliação: o lugar do(a) educador(a)

no processo da avaliação da pós-graduação no Brasil"

\section{REFERENNCIAS}

CHAUÍ, Marilena. Escritos sobre a universidade. São Paulo: Editora UNESP, 2001.

MENDES, Durmeval Trigueiro (Coord.). Filosofia da educação brasileira. Rio de Janeiro: Civilização Brasileira, 1987.

SANTOS, Boaventura de Souza. Pela mão de Alice: o social e o político na pós-modernidade. São Paulo: Cortez, 1997.

Regina Helena Silva Simões é Professora do Programa de Pós-Graduação em Educação da Universidade Federal do Espirito Santo. $O$ endereço eletrônico da autora é: reginahe@terra.com.br

\footnotetext{
Regina Helena Silva Simóes

Da avaliação da educação à educação da avaliação: o lugar do(a) educador(a) no processo da avaliação da pós-graduação no Brasil

Recebido: 3/12/2003

$1^{\text {a }}$ revisão: $5 / 3 / 2004$

Aceite final: 15/4/2004
} 